\title{
Development of Regulatory Mechanism of Food Product Accessible Antioxidants: Lycopene and Curcumin
}

\author{
Pawar V. N., Mane K. A., Ghodke S. V.
}

\begin{abstract}
The lycopene and curcumin are plant base notified nutraceuticals specifically commercialized for pharmaceutical and health benefits base food product development scenario. Antioxidant efficacy driven potential is rightly entrapped by food corporate domain to boost up innovation in favor of consumer satisfaction through health benefits. The consolidated review base information of both the above potent antioxidants is rightly awaiting for transformation as a technology base on their molecular reorientation and active site location. The fractionation leading to all trans and cis forms of lycopene and demethoxy and bisdemethoxy forms of curcumin recorded benchmark study to modulate molecular regulatory mechanism of antioxidant efficacy. The molecular fractionation generative quotients (All trans to cis quotient- 24 to 34and DMC/BDMC quotient-1.94) are emerged out as cutting edge indices of desired antioxidant efficacy. Advance technique specified confirmation $(\mathrm{HPLC})$ recorded quantification of respective components admissible for regulatory mechanism governed by notified quotients which are first time reported in this investigation. The present investigation is coiling around determination of potent antioxidant fractionate quotient of both bioactive compounds as a competent index to formulate food ingredient as an admissible access to justify suitability in food product innovation.
\end{abstract}

Keywords: Antioxidants, lycopene, trans and cis isomers, curcumin, DMC/BDMC quotient, demethoxylation

\section{INTRODUCTION}

$\mathrm{F}_{\text {ood consumption aims to provide nutrients for need }}$ base metabolic activity modulation and also aesthetic value stimulation to ensure food security. Nutritional awareness driven mindset transformation of consumers, rightly focusing on new concept of food products based on hypothesis generative tenet "Let food be a medicine and medicine be a food" to ensure health benefits over and above the nutritional goodness [1]. The specialty group of food coiling around targeted health related functionality recorded vibrant option of innovative research in middle era of $20^{\text {th }}$ century. Functionality base food product development emerged out through food science and technology fostering

Revised Manuscript Received on December 02, 2019

* Correspondence Author

Pawar V. N.*, Dean (F/T), MIT Art, Design and Technology University, Loni Kalbhor, Pune (M.H.) India. Email: vasantnpawar@gmail.com

Mane K. A., Associate Professor (FPPE), MIT School of Food Technology, MIT Art, Design and Technology University, Loni Kalbhor, Pune (M.H.) India Name of the affiliated College or University/Industry, City, Country. Email: kavita83.more@rediffmail.com

Ghodke S. V., Associate Professor (PTSF), MIT School of Food Technology, MIT Art, Design and Technology University, Loni Kalbhor, Pune (M.H.) India. Email: sujataw29@gmail.com research underlined the nomenclature of functional foods to provoke physiological responses and risk bearing efficacy of non-communicable diseases [2]. The functional foods have recorded their inherent efficacy to generate positive impact on consumer health, physical performance and state of mind in addition to nutritive value [1].

The functional food development and commercial exploration has sun-rising potential to rejuvenate present agro-base industry scenario depending upon consumer satisfaction driven value addition (Nutritional and economical), innovation and techno-management conceptualization. Irrespective of broader consensus on need of regulatory mechanism to protect consumer, promote fair trade and encourage product innovation to raise the bar of food industry development, due involvement of functional foods will go long way to compensate the journey of anticipated rejuvenation [3]. The present industrial functional food production scenario recorded data base paucity for summary notified claims of all types of health benefits underlined by lack of clinical studies. The review base hypotheses regarding functional foods highlighting on physical performance, change of mindset and disease prevention and recurrence efficacy generated till to date requires database confirmation to notify targeted ensured health benefits. Consumer physical health and lower susceptibility to chronic diseases is governed by intake of natural agricultural products either in terms of minimal alterations or intensive molecular base processing followed by epidemiological studies. The molecular configuration of various food ingredients based on their activity profile is reflected through efficacy as antioxidant, anti-inflammatory, anti-aging and anti-microbial [4], [5].

Phytochemistry align articulated lycopene and curcumin active molecules being natural bioactive chemical compounds recorded positive impact on human health by inherent potential to prevent, recover and monitor recurrence of non-communicable diseases. Lycopene, a tomato antioxidant and curcumin as a principle turmeric curcuminoid are rightly floating on nutraceutical domain with specific characterization profile for recording vital share in the development of functional foods [6]-[8].

Advanced analytical molecular base research is sincerely awaiting for molecular reorientation of both the above referred antioxidants (Lycopene and curcumin) leading to isomer generative efficacy and active site governance (Methoxylation), respectively. 
Sincere efforts entrapped data, regarding modified forms (Isomers and active site analogues) of both the bioactive components recorded positive impact on human health which is very close to pharmaceutical drugs obtained by purification and characterization processes. The paucity of cutting edge applications in formulation and development of functional foods remained deprived off health benefits confirmatory index dully associated with top to down (Animal to human studies) roadmap model of clinical assessment.

In the present investigation sincere efforts are made to design the research projects based on molecular transformation, characterization and food constituent accessible technology development to justify need base anticipatory antioxidant efficacy. The isomerization of lycopene and demethoxylation of curcumin emerged out as a paradigm to change the philosophy of nutraceutical base formulation of functional foods to justify futuristic contributory share in rejuvenation of agro base industry portfolio.

\section{MATERIALS AND METHODS}

\section{A. Preparation of processed tomato puree: Lycopene case study}

Tomato puree prepared by using deep red colored tomatoes (Local cultivar) through enforced tissue maceration process in screw type extractor, strained (100 mesh sieve) and homogenized as per the method described by [9].

\section{B. Thermal processing of tomato puree}

The homogenized tomato puree was further processed by thermal treatment at $90^{\circ} \mathrm{C}$ for 1 hto assess effect of heat treatment on lycopene isomerization. Lycopene extraction was undertaken by standard extraction procedure using petroleum ether [10].

\section{Characterization of lycopene}

Lycopene characterization with respect to all trans and $c i s$ isomers was assessed for unique type of lycopene extracts (Raw tomato puree and thermal treated puree $-90^{\circ} \mathrm{C}$ for $1 \mathrm{~h}$ ) using High Performance Liquid Chromatography (HPLC) system with non-polar $\mathrm{C}_{30}$ chromatographic column and peaks were eluted with gradient solvent system of methanol: methyl-tert-butyl ether using $472 \mathrm{~nm}$ wavelength [11]. The data and chromatograms were compiled, compared with standard lycopene and quantitative analysis was carried out on the basis of peak area measurements.

\section{Extraction of curcumin from turmeric}

Curcumin extraction is undertaken as per the standardized process technology developed by earlier scientists from the selected cultivars - Salem, Rajapuri and Local [12], [13].

\section{E. Thin layer chromatographic assessment for separation of curcuminoids}

Thin layer chromatographic separation of curcuminoids, leading to three components (Curcumin, Demethoxy curcumin, Bisdemethoxy curcumin), quantified on the basis

of RF values are determined by specified formula as per the method notified by [4].

$$
\mathrm{Rf}=\frac{\text { Distance travelled by spot }}{\text { Distance travelled by solvent }}
$$

\section{F. Characterization of curcumin by high performance liquid chromatography (HPLC)}

Review base sorted out unique salem curcumin sample along with standard curcumin (Sigma Aldrich) were analyzed by HPLC for molecular separation. The selectivity of column $\mathrm{C}_{18}$ [14] based on characterization data of earlier scientists gave way to set up anticipated experimental process governed by $20 \mu \mathrm{l}$ sample injection followed by elution with gradient solvent system (flow rate of $1.0 \mathrm{ml} / \mathrm{min}, 25^{\circ} \mathrm{C}$ temperature) and mobile phase developed with ethanol and methanol. The results are tabulated by wavelength $(254 \mathrm{~nm})$ generative data.

\section{G. Antioxidant activity determination}

Antioxidant activity of both the bioactive compounds is determined by DPPH (Free radical) assay as a commercial experimental asset to determine free radical scavenging efficacy with requisite volume of antioxidant through reduction process. DPPH as a free radical scavenger is allowed to react with known volume of crude antioxidant extract (Lycopene and curcumin) for holding period of 30 minutes. The relative changes in optical density (O.D.) are directly related to free radicals scavenging efficacy and further represented as antioxidant activity facilitated by the equation.

$$
\text { Inhibition }(\%)=\frac{\text { Absorbance }_{\text {Control- }} \text { Absorbance }_{\text {Sample }}}{\text { Absorbance }_{\text {Control }}} \times 100
$$

Per cent inhibition was plotted against concentration and $\mathrm{IC}_{50}$ was calculated on relative volume basis. Ascorbic acid was used as a standard to co-relate $\mathrm{IC}_{50}$ of lycopene enriched puree.

\section{RESULTS AND DISCUSSION}

Food science and technology research philosophy is rightly coiling around targeted functional scenario of specialty group of foods notified as functional foods. Molecular characterization driven efficacy of lycopene and curcumin has vibrant potential ingredient accessibility to modulate formulation mechanism of functional foods in collaboration with advanced processing technology. The strategic action plan of present investigation has also absolutely focused on molecular reorientation of natural antioxidants to underline their functional efficacy.

\section{A. Characterization of lycopene (All trans and cis} isomers)

HPLC chromatogram profile generative data of reference and tomato puree lycopene presented in following figures (Fig. 1, 2 and 3) clearly 
indicates the absolute identification of all trans isomers in tomato puree and standard lycopene (Sigma Aldrich). Remarkable deviation in cis isomer profile was recorded regarding considerable projection of 13-cis isomer against relative non identifiable scenario of 5-cis,

9-cis and 15-cis isomers in case of tomato puree lycopene. Moreover similar isomer profile exhibited by raw and processed tomato puree lycopene recorded encouraging results to justify minimal effect of heat treatment on isomerization. The diversity data on isomerization profile (Table 1) also provided an option to regulate all trans to $\mathrm{cis}$ quotient (25.84 and 33.40 for raw and processed tomato puree, respectively) as a efficacy determining index. Moreover $22 \%$ deviation in 13-cis isomer due to heat processing responsible to monitor said quotient though appeared to be contradictory against earlier pharmaceutical researchers [15], [16] recorded to be a vibrant achievement for food technologist on the basis of controlled process parameters $\left(90^{\circ} \mathrm{C}\right.$ for $\left.1 \mathrm{~h}\right)$ to develop differential processing technology of tomato puree.

Table I: Isomeric quotient profile of tomato puree lycopene

\begin{tabular}{|c|c|c|c|c|c|}
\hline \multirow[t]{2}{*}{ Sample } & \multirow{2}{*}{$\begin{array}{l}\text { Lycopene } \\
\text { yield } \\
\text { (mg/100g) }\end{array}$} & \multicolumn{2}{|c|}{$\begin{array}{l}\text { Isomeric content of } \\
\text { Lycopene }(\%)\end{array}$} & \multirow{2}{*}{$\begin{array}{l}\text { Quotient } \\
\text { (Trans/ } \\
\text { cis) }\end{array}$} & \multirow{2}{*}{$\begin{array}{c}\text { DPPH radical } \\
\text { scavenging } \\
\text { activity } \\
{\left[\mathrm{IC}_{50}(\mu \mathrm{g} / \mathrm{ml})\right]}\end{array}$} \\
\hline & & 13-cis & $\begin{array}{c}\text { All } \\
\text { trans }\end{array}$ & & \\
\hline $\begin{array}{l}\text { Lycopene } \\
\text { extract from } \\
\text { raw tomato } \\
\text { puree }\end{array}$ & 2.85 & 3.73 & 96.27 & 25.84 & 223.1 \\
\hline $\begin{array}{l}\text { Lycopene } \\
\text { extract from } \\
\text { thermally } \\
\text { processed } \\
\text { tomato } \\
\text { puree }\left(90^{0} \mathrm{C}\right. \\
\text { for } 1 \mathrm{~h}) \\
\end{array}$ & 5.51 & 2.91 & 97.09 & 33.45 & $\begin{array}{c}90.91 \\
\text { (2.5 fold rise } \\
\text { in antioxidant } \\
\text { efficacy) }\end{array}$ \\
\hline $\begin{array}{l}\text { Lycopene } \\
\text { (Sigma } \\
\text { Aldrich) }\end{array}$ & --- & $\begin{array}{l}3.85 \\
(13 \text { cis: } \\
2.23)\end{array}$ & 96.15 & 24.97 & \\
\hline
\end{tabular}

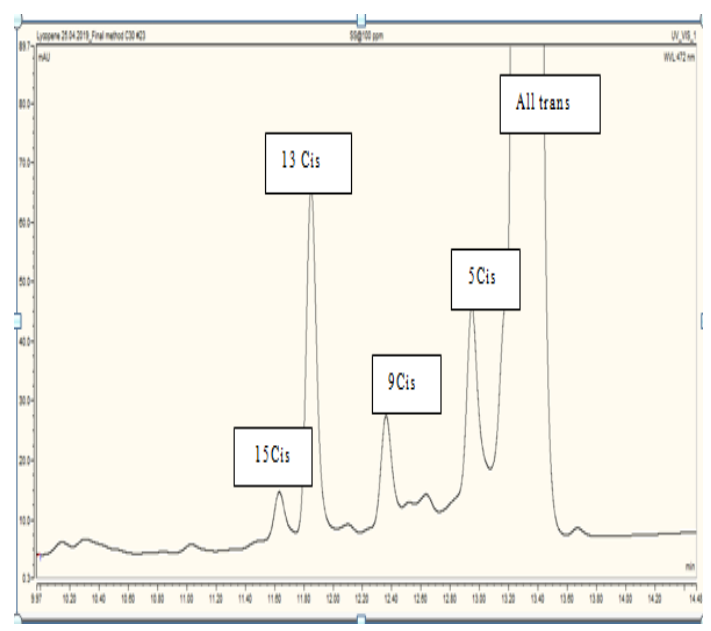

Fig.1. HPLC chromatogram of lycopene standard (Sigma Aldrich)

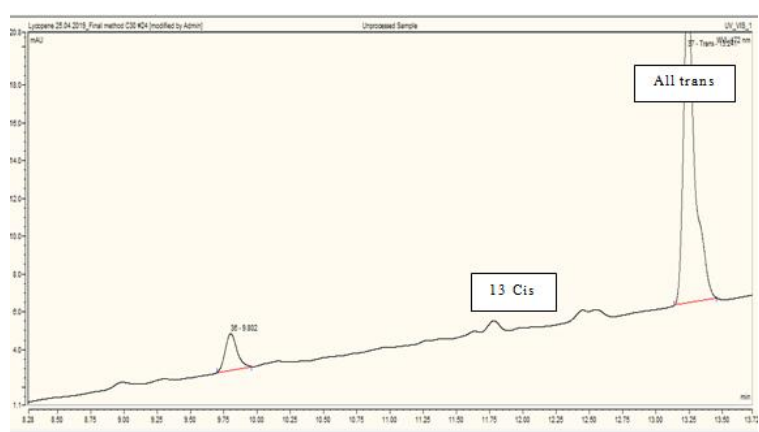

Fig.2. HPLC chromatogram of raw tomato puree lycopene

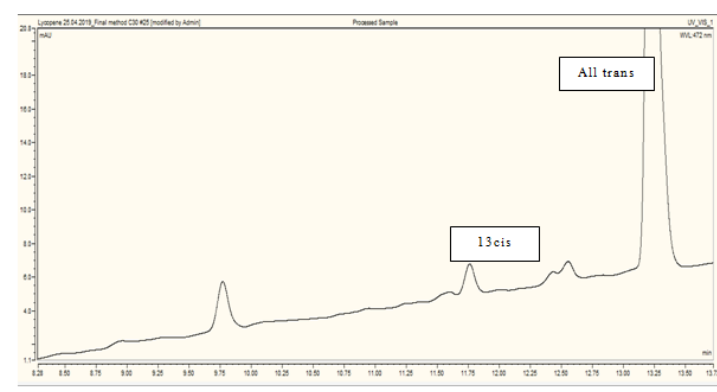

Fig. 3. HPLC chromatogram of processed tomato puree lycopene

\section{B. Curcumin characterization: Fraction base}

The anticipated differential characterization of curcumin required for modulating antioxidant efficacy, as a targeted value of said investigation, sincere efforts are reflected through presentation of TLC data in table no.2. The RF values depicted in said table recorded as quantifying modem of respective active component. The comparative trend of RF values (Salem and standard curcumin)recorded in data appeared to be very close to optimum level accuracy to standard curcumin in the range of 0.75 to $0.71,0.55$ to 0.65 and 0.27 to 0.32 in case of relative components specified as curcumin, demethoxy curcumin and bisdemethoxy curcumin respectively [17]. The said data also confirms the selectivity of salem cultivar as a competent antioxidant against rajapuri and local cultivars that was rightly sorted out on the basis of literature reviewed and concluding remarks of presented data respectively. More over the said data also provides an option to figure out other type of relevant parameter reflecting directly on antioxidant efficacy of curcumin to justify as bioactivity of food ingredient. The active site governing curcumin fractionation leading to demethoxy curcumin (DMC) and bisdemethoxy curcumin (BDMC) also recorded a unique type of characterization admissible for food technological researcher.

Inherent efficacy of curcumin is function of its molecular integrity based on methylated active sites (aromatic phenyl end rings). The standard curcumin associated inherent analogues referred as DMC and BDMC has capacity to provide antioxidant efficacy depending upon their contributory share and other

Published By:

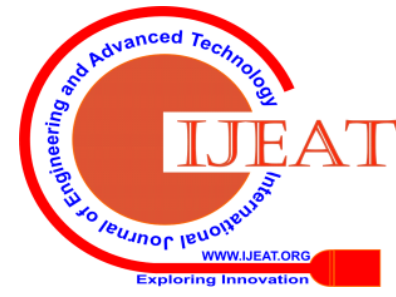


Development of Regulatory Mechanism of Food Product Accessible Antioxidants: Lycopene and Curcumin

processing parameters (time and temperature- $64^{\circ} \mathrm{C}$ ) [18]. More over optimum efficacy governing index likely to be presented as DMC/BDMC quotient has unique type of feature to justify potential antioxidant efficacy getting deviated during processing of food products as an active ingredient because of application of heat. The data on to notify the impact of processing technology. DMC/BDMC quotient value (1.94) of salem cultivar recorded to be very close to reference value of standard

Commercial curcumin review base reported value of DMC/BDMC quotient admissible to calculate on fractionation of DMC and BDMC $(18 / 5=3.6)$ [19] that might have represented by quoting Sigma Aldrich as a analogues appeared to be at par with the standard that may be expected in multiple times. Heat treatment being one of the prime parameter of processing may have direct impact on demethoxylation causing deviation in antioxidant efficacy. Monitoring of antioxidant efficacy of curcumin molecule to cutting edge bismethoxylation during successive demethoxylation results in sustainability of DMC/BDMC quotient value responsible for optimum free radical scavenging efficacy. This provides challenging option to standardize newly developed curcumin fortified food products to preserve anticipated antioxidant effect to justify its nutraceutical efficacy. This may be accepted as a further investigation option to upgrade/ monitor antioxidant efficacy either by biotechnological and nano technological applications in coordination with advance processing scenario.

HPLC base curcumin characterization on the basis of standard parameters (Retention time and area) depicted in table no. 3 indicates that the percent area occupied by standard (Sigma Aldrich- 100\%) and salem cultivar curcumin $(99.1920 \%)$ appeared to be at par, reflecting yield as $42.60 \mathrm{~g} / 100 \mathrm{~g}$ weight of extract obtained from successive extraction process by using $6 \mathrm{~g}$ crude turmeric powder. The standard curcumin reference generative percent yield of curcumin in powder base extract recorded as $42.60 \mathrm{~g} / 100 \mathrm{~g}$ is appeared to be anticipated outcome of the said research project. This may reflects directly on natural strength of Salem cultivar as a commercially viable source of curcumin.

Moreover, amongst two predominant absorbance peaks of salem cultivar, one represented by largest area is reflected as curcumin on the basis of similar percent area values and other as non-detectable, may be confined to analogous components. Further critical investigation for identification as core components will go a long way to justify the process of demethoxylation modulation exclusively in the interest of antioxidant efficacy regulatory mechanism.

Table II: Curcumin fraction profile of turmeric cultivars

\begin{tabular}{|l|l|l|l|}
\hline Sample & Rf values & DMC/ & Antioxidant \\
\hline
\end{tabular}
DMC/BDMC quotient from table no. 2 is self- explanatory curcumin (2.03). reference curcumin. The requisite proportion of both the

\begin{tabular}{|l|l|l|l|l|l|}
\hline & C & DMC & BDMC & $\begin{array}{l}\text { BDMC } \\
\text { Quotie } \\
\text { nt }\end{array}$ & $\begin{array}{l}\text { activity(\% } \\
\text { Inhibition) } \\
\text { (DPPH) }\end{array}$ \\
\hline Salem & 0.71 & 0.62 & 0.32 & 1.94 & 52.31 \\
\hline $\begin{array}{l}\text { Standard } \\
\text { curcumin }\end{array}$ & 0.75 & 0.55 & 0.27 & 2.03 & 61.70 \\
\hline
\end{tabular}

*Each observation is an average of three determinations. $\mathbf{C}=$ Curcumin

DMC = Demethoxycurcumin

BDMC= Bisdemethoxycurcumin

Table III: HPLC base curcumin characterization

\begin{tabular}{|c|c|c|c|c|c|c|}
\multicolumn{7}{|c|}{ (Salem) } \\
\hline $\begin{array}{c}\text { Curcumi } \\
\text { n base }\end{array}$ & $\begin{array}{c}\text { Expect } \\
\text { ed No. } \\
\text { of Peak }\end{array}$ & $\begin{array}{c}\text { Identific } \\
\text { ation of } \\
\text { Peak }\end{array}$ & $\begin{array}{c}\text { Retenti } \\
\text { on time } \\
\text { (Min) }\end{array}$ & $\begin{array}{c}\text { Area } \\
(\mathbf{m A U} \\
\text { S) }\end{array}$ & $\begin{array}{c}\text { Area } \\
(\%)\end{array}$ & $\begin{array}{c}\text { Yield } \\
\text { Curcu } \\
\text { min } \\
(\%)\end{array}$ \\
\cline { 2 - 7 } & 1 & $\begin{array}{c}\text { Unknow } \\
\text { Salem }\end{array}$ & 2.243 & $\begin{array}{c}162.474 \\
0\end{array}$ & $\begin{array}{c}0.808 \\
0\end{array}$ & \\
\cline { 2 - 7 } & 2 & $\begin{array}{c}\text { Curcumi } \\
\mathrm{n}\end{array}$ & 3.615 & $\begin{array}{c}1.9946 \\
99.19\end{array}$ & 42.60 \\
\hline $\begin{array}{c}\text { Sigma } \\
\text { Aldric } \\
\text { h std } \\
\text { curcu } \\
\text { min }\end{array}$ & 1 & Curcumi \\
$\mathrm{n}$ & 3.601 & 4.5802 & 100.0 & \\
& & & & & 00 & \\
\hline
\end{tabular}

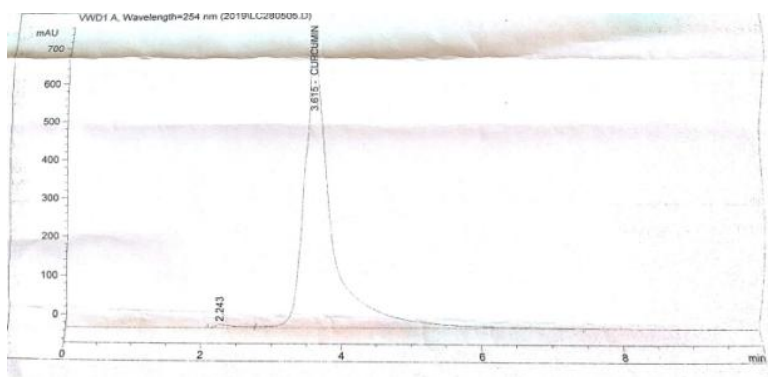

Fig. 4. HPLC chromatogram of curcumin (Salem)

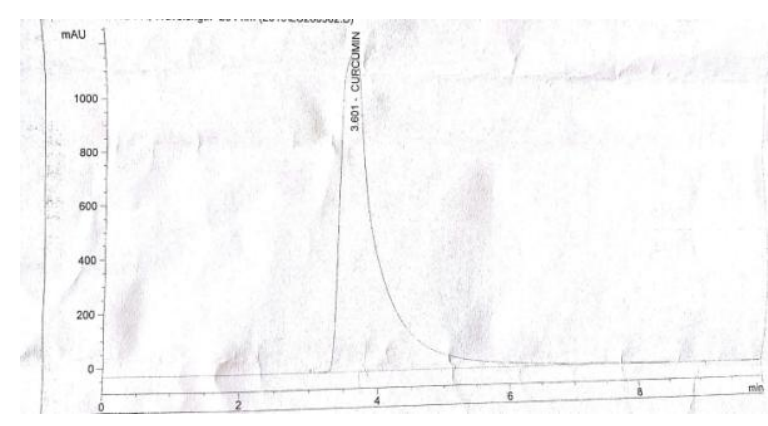

Fig. 5. HPLC chromatogram of curcumin (Standard)

\section{CONCLUSION}

The possibility of lycopene and curcumin, being plant base bioactive compounds, was assessed with isomerization and methoxylation regulatory process technology to justify their suitability as food ingredient through molecular reorientation. The critical review base information was also made suitable to transform it as a technology. 
The isomer base trans/cis quotient (25.84 and 33.40 for raw and processed tomato puree) of lycopene and demethoxylation base DMC/BDMC quotient (1.94 and 2.03 for salem cultivar and standard curcumin) emerged out from the present investigation provided probable molecular regulatory mechanism to modulate potential antioxidant efficacy of both the bioactive compounds. The advance techniques for molecular fractionation of both the active compounds referred as HPLC and TLC recorded confirmatory quantification of respective components admissible for regulatory mechanism governed by notified quotients which are first time reported in this investigation. This type of marvelous research achievements will go long way to boost up consumer and need base innovative food product processing technology development. The further horizon of said research is coiling around production of lycopene and curcumin fortified fruit juice beverages (Data is awaiting for further compilation).

\section{REFERENCES}

1. F. Rincon-Leon, Encyclopedia of food sciences and nutrition. $2^{\text {nd }}$ Edn, 2003 Available: https://www.sciencedirect.com.

2. M. Nicoletti, (2012). Nutraceutical and botanical overview and perspectives. Int. J Food Sci. Nutr. 1, pp. 2-6.

3. A. Vicentini, L. Liberatore, and D. Mastrocola (2016). Functional foods: trends and development of the global market. Ital. J. Food Sci.28, pp. 338-351.

4. O. D. Omodamiro and U. Amechi (2013). The phytochemical content, antioxidant, antimicrobial and anti-inflammatory activities of Lycopersicon esculentum (Tomato). Asian J Plant Sci. Res. 3(5), pp 70-81.

5. S. S. Moselhy, S. Razvi, N. Hasan, K. S Balamash, K. O.Abulnaja, S. S. Yaghmoor, M. A. Youssri, T. A. Kumosani and A. L. Al-Malki (2018). Multifaceted role of a marvel golden molecule, curcumin: a review. Indian J Pharm Sci. 80(3), pp. 400-411.

6. A. R. Davis, W. W. Fish, and V. P. Perkins (2003). "A rapid spectrophotometric method for analyzing lycopene content in tomato and tomato". Postharvest Bio. Technol. 28, pp. 425-430.

7. A. V. Rao and L. G. Rao (2007). Review on carotenoids and human health. Pharmacol. Res., 55 (3), pp. 207-216.

8. R. P. Sing and D. A. Jain (2012). Evaluation of antimicrobial activity of curcuminoids isolated from turmeric, Int. J. Pharma. Life Sci., 3(1), pp. 1368-1376.

9. K. A. Mane, and V. N. Pawar, (2018). "Study on effect of processing parameters on lycopene content of tomato puree". Int. J Res. Anal. Rev. 5 (3), pp. 512-517.

10. S. K. Thimmaiah. Standard methods of biochemical analysis, Kalyani Publishers, 2016, pp. 53-62.

11. M. K. Roh, M. H. Jeon, J. N. Moon, W. S. Moon, S. M. Park, and J. S Choi (2013). A simple method for the isolation of lycopene from Lycopersicon esculentum. Bot Sci. 91 (2), pp. 187-192.

12. S.J. Kulkarni, K.N. Maske, M.P. Budre, and R.P. Mahajan (2012). "Extraction and purification of curcuminoids from Turmeric (curcuma longa L.)". Int. J. Pharmacol. Pharma. Tech. 1(2), pp. 81-84.

13. S. V. Ghodke and V. N. Pawar (2018). "Studies on food value base curcumin extraction for commercial exploration". J. pharma. phyto. 7(6), pp. 1173-1176.

14. H. Soni, S. Patel, K. Mishra, G. Mayak and A. K. Singhai (2011). Qualitative and quantitative profile of curcumin from ethanolic extract of Curcuma Longa, International Res. J. Pharma. 2(4), pp. 180-184.

15. J. Shi and M. L. Maguer (2010). "Lycopene in tomatoes: Chemical and physical properties affected by food processing," pp.1-42. Available: http://www.tandfonline.com/

16. G. B. Martinez-Hernandez, M. Boluda-Aguilar, A. Taboada-Rodriguez, S. Soto-Jover, F. Marin-Iniesta, and A. Lopez-Gomez, (2015) "Processing, packaging, and storage of tomato products: influence on the lycopene content". Food Engg. Rev. do 10.1007/s12393-015-9113-3

17. S. Revathy, S. Elumalai, Merina Benny and Benny Antony (2011). Isolation, purification and identification of curcuminoids from turmeric (Curcuma longa L.) by column chromatography. J Expt Sci., 2 (7), pp 21-25.
18. B. T. Kurien, H. Matsumoto and R. H. Scofield, (2017). "Nutraceutical value of pure curcumin". Pharmacognasy Magazine. pp. 161-163.

19. P. Basnet, and N. S. Basnet (2011). "Curcumin: anti- inflammatory molecule from a curry spice on the path to cancer treatment". Molecules.16, pp. 4567-4598.

\section{AUTHORS PROFILE}

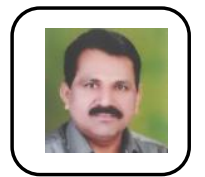

Dr. Vasant N. Pawar is presently working as, Dean (F/T) and Principal (MITSoFT) at MIT Art, Design and Technology University, Pune under private education domain. Being an inherent food technologist he has discharged his services as Professor, Head of the Department and Dean Academic at various Universities of State and National repute. Post harvest technology of fruits and vegetables, Nutraceutical base food product development are the focusing arena of education and research career. $2+3$ patents and 106 research articles are at his credit. He has also been bestowed with ICAR best teacher and best researcher awards. Cornell University, USA visiting Professor recognition underlined his overseas university relationship for invitation as a subject matter specialist at national and international level conferences. AFST(I), Mysore and NSI, Hyderabad as a life membership partner provides an opportunity for self-updating of education and research scenario.

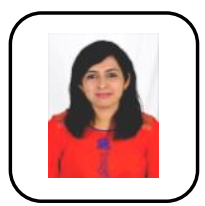

Kavita A. Mane is working as Associate Professor at MIT ADT University in the department of Food Process and Product Engineering. She has published 11 research papers in peer reviewed journals in the field of food science and technology. She is the member of professional bodies' like AFST(I), ISAE, NSI, ISHRAE and AIASA. She has participated in various conferences and seminars and is the recipient of first prize for paper presentation in $23^{\mathrm{r}}$ National Convention of Agricultural Engineers.

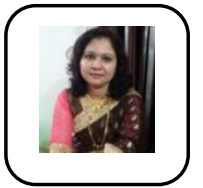

Sujata V. Ghodke is Associate Professor and In-charge Head of Department of Patronage of Traditional \& Specialty Food, discharging services in MIT School of Food Technology with utmost efficiency. She is food technologist with Gold Medal in M.Tech (Food Science \& Technology). She is life member of Association of Food Scientists and Technologist, India, AIASA and Nutrition Society of India. She has participated in varying conferences, trainings and seminars associated with food processing, safety and quality for her academic enrichment. She has 9 research papers at her credit published in well-known food journals. 